\title{
Prevalence of Tidal Expiratory Flow Limitation in Preschool Children with and without Respiratory Symptoms: Application of the Negative Expiratory Pressure (NEP) Method
}

\author{
A. JIŘIČKOVÁ ${ }^{1}$, J. ŠULC ${ }^{2}$, P. POHUNEK ${ }^{2}$, O. KITTNAR $^{1}$, A. DOHNALOVÁ ${ }^{1}$, \\ J. KOFRÁNEK ${ }^{3}$
}

${ }^{1}$ Department of Physiology, First Medical Faculty, ${ }^{2}$ Department of Pediatrics, Second Medical Faculty and University Hospital Motol, ${ }^{3}$ Department of Pathophysiology, First Medical Faculty, Charles University, Prague, Czech Republic

Received June 6, 2007

Accepted May 21, 2008

On-line July 18, 2008

\begin{abstract}
Summary
Negative expiratory pressure (NEP) applied at the mouth during tidal expiration provides a non-invasive method for detecting expiratory flow limitation. Forty-two children were studied, i.e. 25 children with different respiratory symptoms (R) and 17 without any respiratory symptoms (NR). Children were examined without any sedation. A preset NEP of $-5 \mathrm{~cm} \mathrm{H}_{2} \mathrm{O}$ was applied; its duration did not exceed duration of tidal expiration. A significance of FL was judged by determining of a flow-limited range (in \% of tidal volume). FL was found in $48 \%$ children of $\mathrm{R}$ group. No patient of the NR group elicited FL ( $P<0.001 R$ vs. $N R)$. The frequency of upper airway collapses was higher in $R$ group (12 children) than in NR group (5 children). In conclusion, a high frequency of tidal $F L$ in the $R$ group was found, while it was not present in NR group. A relatively high frequency of expiratory upper airway collapses was found in both groups, but it did not differ significantly. NEP method represents a reasonable approach for tidal flow limitation testing in non-sedated preschool children.
\end{abstract}

\section{Key words}

Preschool children - Respiratory disorders - Expiratory flow limitation • Negative expiratory pressure technique

\section{Corresponding author}

A. Jiřičková, Institute of Physiology, First Faculty of Medicine, Charles University, Albertov 5, 12800 Prague 2, Czech Republic. E-mail: adriana.jirickova@If1.cuni.cz

\section{Introduction}

In healthy individuals, most parameters of respiratory function remain remarkably constant when related to either surface area or body size, reflecting the fact that respiration is closely adjusted to the metabolic requirements of the body. However, the underlying factors determining these parameters may vary considerably according to age (Gollogly et al. 2004). Following establishment of regular respiration, alveolar ventilation, minute ventilation and work of breathing are similar to that of an adult; however, it must be remembered that the relatively large surface area to body mass ratio and rapid growth in infants are such that oxygen consumption and metabolic rate are relatively high compared with those parameters in adults. The respiratory system is by no means simply a miniaturized version of that in adult, since developmental changes in respiratory physiology, particularly with respect to the influence of the upper airways, the compliant chest wall, dynamic elevation of functional residual capacity (FRC) and the strength of various respiratory reflexes.

Nearly all lung function tests which are routinely applied in older children and adults have been adapted to the special needs of small children and infants, particularly to their inability to cooperate during breathing maneuvers. While theoretically the basics for routine lung function tests exist, still very few laboratories perform these tests of infant lung function. 
This is mainly due to the lack of reference values in a given population as well as the problematic training of technicians, the need for sedation for most of the test, and the technically demanding and time consuming test procedures. (Stocks 2006)

The NEP technique is a simple method to detect expiratory flow limitation (FL), which does not require patient cooperation. The highest pulmonary ventilation that a subject can achieve is ultimately limited by the highest flow rates, which can be generated. Most normal adults and children do not exhibit expiratory flow limitation even during maximal exercise. In contrast, patients with respiratory disorders may exhibit FL even at rest as first suggested by Hyatt (1961). This was based on his observation that patients with severe COPD often breathe tidally along their descendent part of maximal expiratory flow-volume curve. The presence of expiratory FL during tidal breathing promote dynamic pulmonary hyperinflation, with concomitant increase of inspiratory work, impairment of inspiratory muscle function, and adverse effects on hemodynamics. The studies on expiratory FL in children are rare (Braggion et al 1998, Jones et al. 2000, Goetghebeur et al. 2002).

Conventionally, FL is assessed by comparison of the tidal expiratory flow-volume (V'-V) curves with the corresponding maximal expiratory flow-volume curves. The patients in whom at comparable lung volumes tidal flows are the same or higher than those obtained during the forced vital capacity (FVC) maneuver are considered flow limited (Hyatt 1961). However, this approach has both theoretical and practical limitations (Milic-Emili 2000). A reliable method to detect FL has been proposed (Valta et al. 1994, Kolouris et al. 1995), which is based on application of negative expiratory pressure (NEP) at the mouth during tidal expiration. It provides a simple approach in detecting intrathoracic tidal expiratory flow limitation, which does not require patient's cooperation and hence it can be used in children. The application of NEP during expiration increases the pressure gradient between the alveoli and the airway opening. The patients in whom NEP elicits an increase in flow compared to the preceding control tidal expiration are not flow-limited (NFL). In contrast, the patients in whom the expiratory flow does not increase after NEP application are flowlimited (FL) (Eltayara et al. 1996, Milic-Emili 2000). Using this method the presence of tidal expiratory flow limitation has been investigated in a variety of adult respiratory disorders. These studies have shown that tidal FL is commonly present in patients with respiratory diseases such as chronic obstructive pulmonary disease (Eltayara et al. 1996, Baydur and Milic-Emili 1997, Diaz et al. 2000, Eltayara et al. 2001), bilateral pulmonary bronchiectasis (Kolouris et al. 2003), obesity (Pankow et al. 1998, Ferretti et al. 2001) euthyroid goitre (Torchio et al. 2003), acute left heart failure (Duguet et al. 2000) and obstructive sleep apnea syndrome (Insalaco et al. 2005). Such patients often exhibit severe chronic dyspnea, exercise limitation and orthopnea.

The clinical application of the NEP technique and its role in the assessment of dynamic hyperinflation (DH) has been recently extensively reviewed (Calverley and Kolouris 2005). Three studies employed NEP technique also during childhood and infancy. Braggion et al. (1998) used the NEP technique $\left(-4 \mathrm{~cm} \mathrm{H}_{2} \mathrm{O}\right.$ NEP) in 10 sedated supine infants (aged 4 to 15.5 months) with cystic fibrosis (CF). Only 1 exhibited tidal FL. Goetghebeur et al. (2002) showed that in 17 seated children and adolescents (aged 6-18 years) with $\mathrm{CF}$ (NEP ranging from -3 to $-7 \mathrm{~cm} \mathrm{H}_{2} \mathrm{O}$ ) FL was absent at rest. In contrast, according to the same study, tidal FL exhibited by 3 of the $7 \mathrm{CF}$ patients older than 12 years. All FL patients had markedly reduced inspiratory capacity (IC) and $\mathrm{FEV}_{1}$ as well. The NEP technique was also used in 4 infants to verify the validity of FL assessed during forced expiratory maneuvers performed by the jacket method (Jones et al. 2000).

The aim of the present study was to assess the prevalence of tidal FL during resting breathing in a group of preschool children with various respiratory symptoms (R). As a control group 17 children without any acute or chronic respiratory symptoms (NR) were studied. We also assessed if the NEP technique is applicable in preschool children without any sedation.

\section{Subjects and Methods}

\section{Design of the pediatric cohort and data collection}

Forty two children admitted at the Department of Pediatrics of the University Hospital Motol were tested. The project was approved by the local Ethics Committee of the University Hospital Motol and by the Ethics Committee of the Internal Grant Agency of the Czech Ministry of Health. The Informed Consent was obtained from the parents of all our patients. Children were divided into two groups.

Respiratory symptoms (R) group consisted of 25 children (14 boys, 11 girls) with various respiratory symptoms (Table 1). Fourteen out of 25 patients (56\%) 


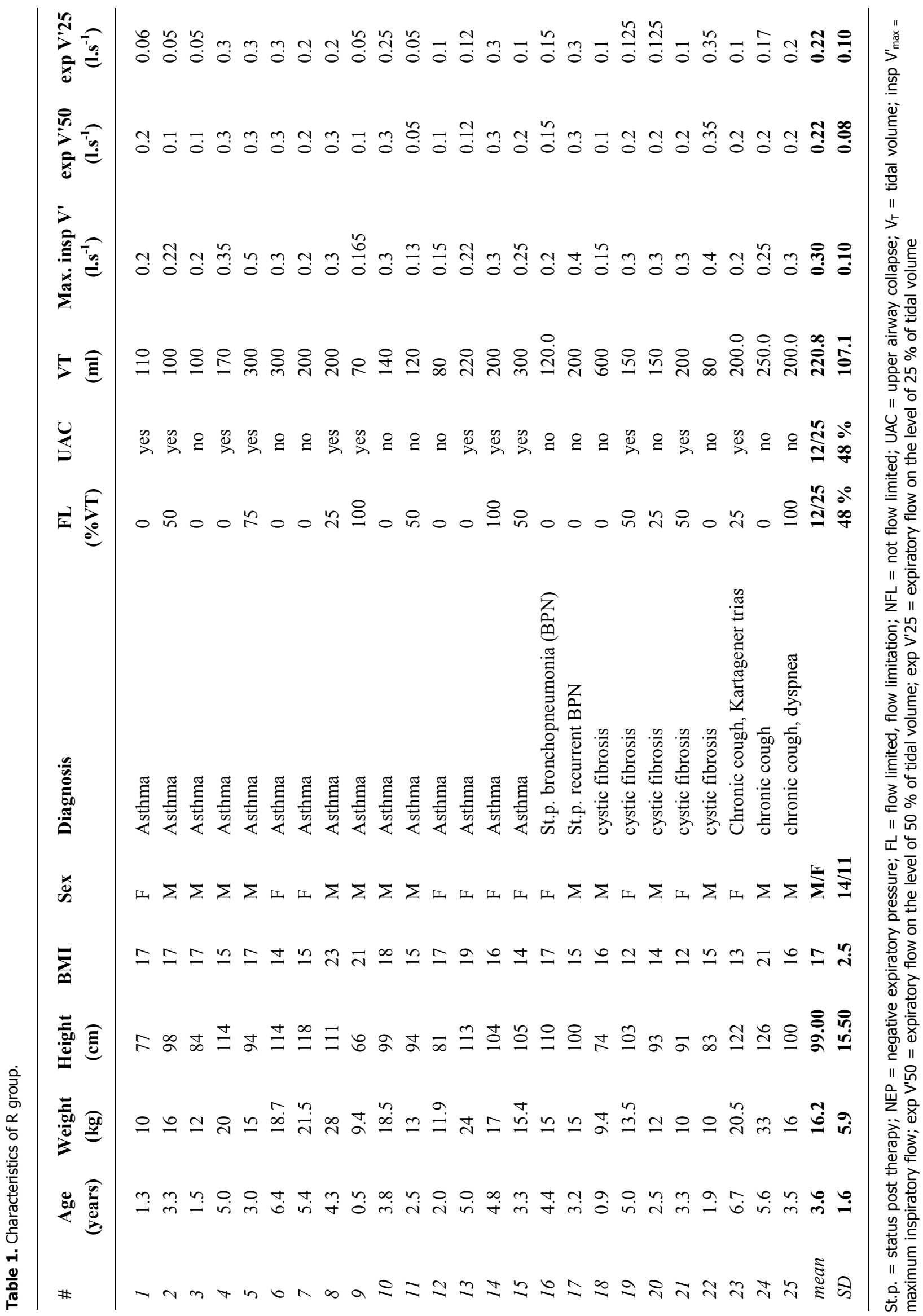




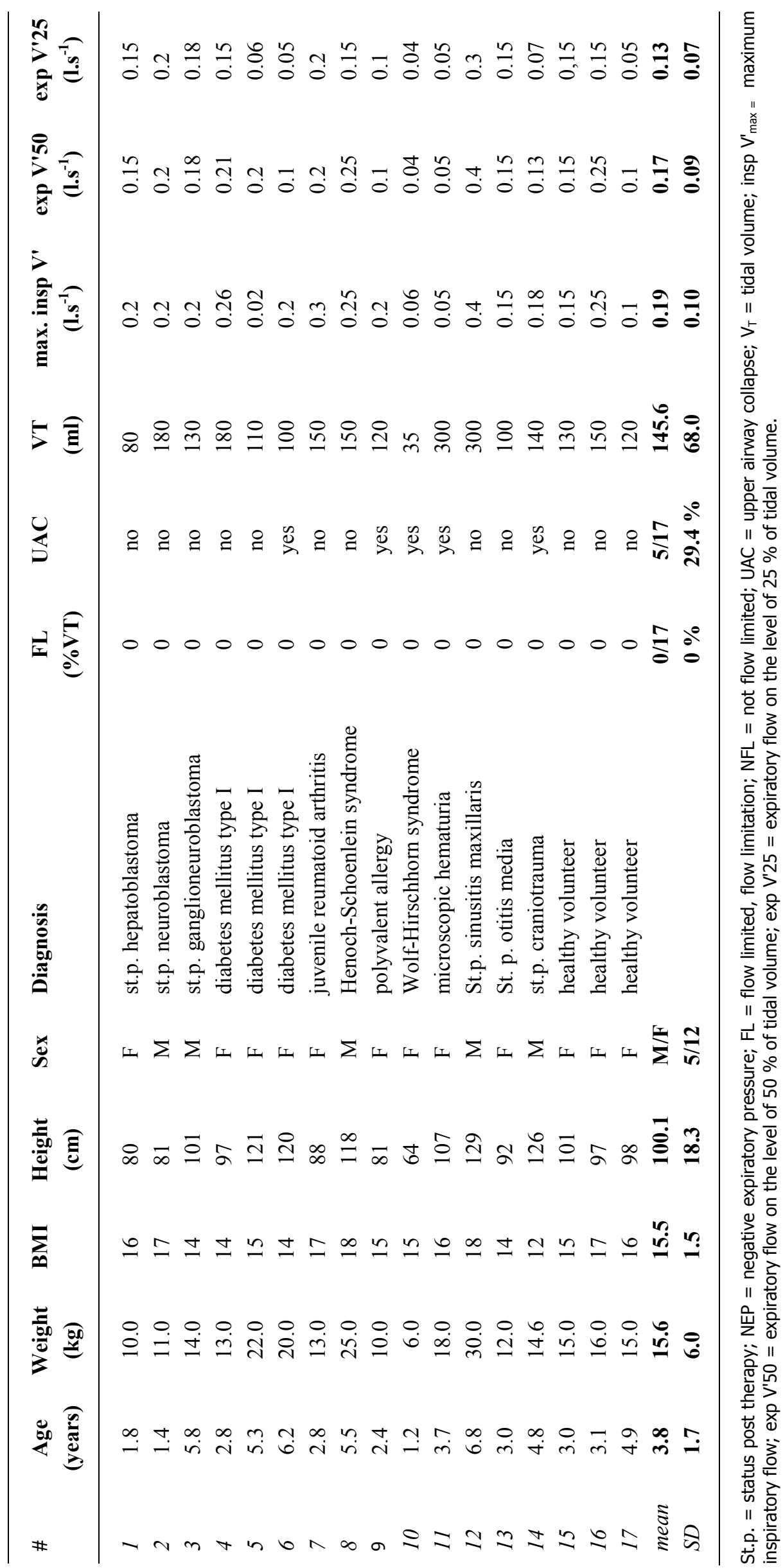


were on combined bronchodilator/anti-inflammatory therapy; 5 children (20\%) of RD group were on bronchodilator monotherapy and just one subject (4\%) underwent anti-inflammatory monotherapy by oral corticosteroid. Only 5 patients $(20 \%)$ were without any therapy. Six of 25 children have undergone a flexible bronchoscopy (24\%) and one had been previously mechanically ventilated (4\%). All patients of $\mathrm{R}$ group had abstained from use of inhaled bronchodilator therapy for at least 6 hours prior to the study.

Non-respiratory symptoms (NR) group consisted of 17 children ( 5 boys, 12 girls) without respiratory symptoms at the time of the study (Table 2). The age, height, body weight, body mass index and gender ratio between the groups did not differ significantly (Tables 1 and 2).

At the time of the study all patients were in a stable clinical condition.

\section{Negative expiratory pressure technique measurements}

All children were tested in a semi-recumbent position in the arms of their mothers or laboratory technicians. Children were conscious without any sedation. A closely fitting facemask was placed over their nose and mouth. The pattern of breathing was on-line monitored on a computer screen. Flow and pressure signals were displayed by ANADAT software (RHTInfo-Dat Inc., Montreal, Canada). A minimal interval of 2 min was required for subjects to reach a steady-state condition. After that interval a preset level of $-5 \mathrm{~cm} \mathrm{H}_{2} \mathrm{O}$ NEP was applied at the onset of a normal quiet expiration. NEP was triggered manually about 20-60 ms after the reversal of inspiratory to expiratory flow. The total duration of NEP application did not exceed the duration of tidal expiration. The minimal number of measurements in every particular session was five.

Airflow was measured with the heated pediatric pneumotachograph Jaeger PT 180, i.d. $35 \mathrm{~mm}$ (JaegerVIASYS) connected to the differential pressure transducer Validyne model MP 45-14-871, range $\pm 2 \mathrm{~cm}$ $\mathrm{H}_{2} \mathrm{O}$ (Validyne Engineering Sales Corp., Northridge, CA). Flow and pressure signals were converted using AD converter model EA-01 (The Professional, Taiwan).

Flow, pressure and volume (obtained by numerical integration of the flow signal) records were reconstructed by Sigma Plot software (SPPS Inc., Germany). The flow-volume $\left(\mathrm{V}^{\prime}-\mathrm{V}\right)$ loops generated with
NEP were compared by a superimposition with the immediately preceding breath. If the flow with NEP increased throughout expiration the patient was considered NFL (Fig. 1a). In contrast, when tidal expiratory flow with applied NEP did not change within the control tidal volume $\left(\mathrm{V}_{\mathrm{T}}\right)$ range, the subject was considered FL (Fig. 1b). The degree of FL was measured in the ranges of $0-25 \%$ of $\mathrm{V}_{\mathrm{T}}, 25-50 \%$ of $\mathrm{V}_{\mathrm{T}}, 50-75 \%$ of $\mathrm{V}_{\mathrm{T}}$ and $>75 \%$ of $\mathrm{V}_{\mathrm{T}}$. Therefore, FL encompassed in the mentioned ranges of tidal $\mathrm{V}_{\mathrm{T}}$, which persisted all duration of mentioned part of tidal breath volume was considered as $<25 \%$ (marked as FL 0), 25-50\% (marked as FL 25), $50-75 \%$ (marked as FL 50$)$ and $>75 \%$ of $\mathrm{V}_{\mathrm{T}}$ (marked as FL 75), respectively. If FL encompassed the complete $V_{T}$ the degree of FL was in $100 \%$ of $\mathrm{V}_{\mathrm{T}}$ (marked as FL 100). In NFL subjects the degree of FL was $0 \% \mathrm{~V}_{\mathrm{T}}$ (Tables 1 and 2). Another approach of a quantification of FL, i.e. an assessment of $\% \mathrm{~V}^{\prime}$ peak (Insalaco et al 2005) has not been used in the present study as this method was originally used in group of adult patients suffered from obstructive sleep apnea syndrome (OSA) only.

A transient increase in flow (spike) was often observed immediately after the application of NEP (Figs 1a, 1b, 1c), which reflects sudden reduction in volume of the compliant oral and neck structures as well as an artifact due to common mode rejection ratio (CMRR) (Peslin et al. 1984, Farré et al. 1989).

The initial spike after the application of NEP was sometimes followed by one or more transient reductions of flow below control level. This finding reflects upper airway (UA) expiratory obstruction (Fig. c). If this phenomenon was observed, the patient was considered have "upper airway collapse or narrowing" (Baydur and Milic-Emili 1997, Baydur et al 2004). When the transient initial reductions in flow due to expiratory UAC were more prominent with NEP than under control conditions (Fig. 1c), the subject was considered as having expiratory extrathoracic UAC but not intrathoracic FL. If no expiratory extrathoracic UAC appeared on repeated NEP tests during any 2-min session, the patient was considered as "without expiratory extrathoracic UAC".

In order to describe better parameters of tidal breathing, the following indices were also measured: tidal volume $\left(\mathrm{V}_{\mathrm{T}}\right)$; maximum inspiratory flow (insp $\mathrm{V}_{\text {max }}^{\prime}$ ); expiratory flow on the level of $50 \%$ of tidal volume $\left(\mathrm{V}_{\mathrm{E}}{ }^{\prime} 50\right)$; expiratory flow on the level of $25 \%$ of tidal volume $\left(\mathrm{V}_{\mathrm{E}}^{\prime} 25\right)$. 


\section{a) not flow-limited}

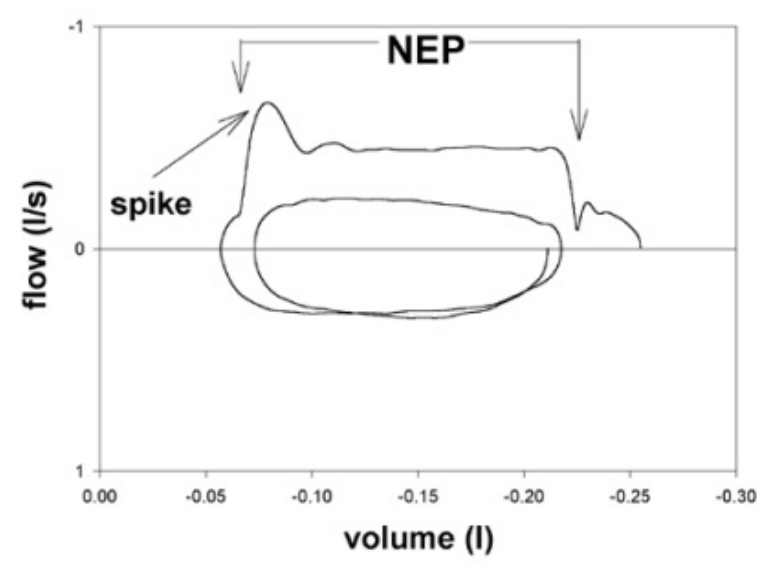

\section{b) flow-limited}

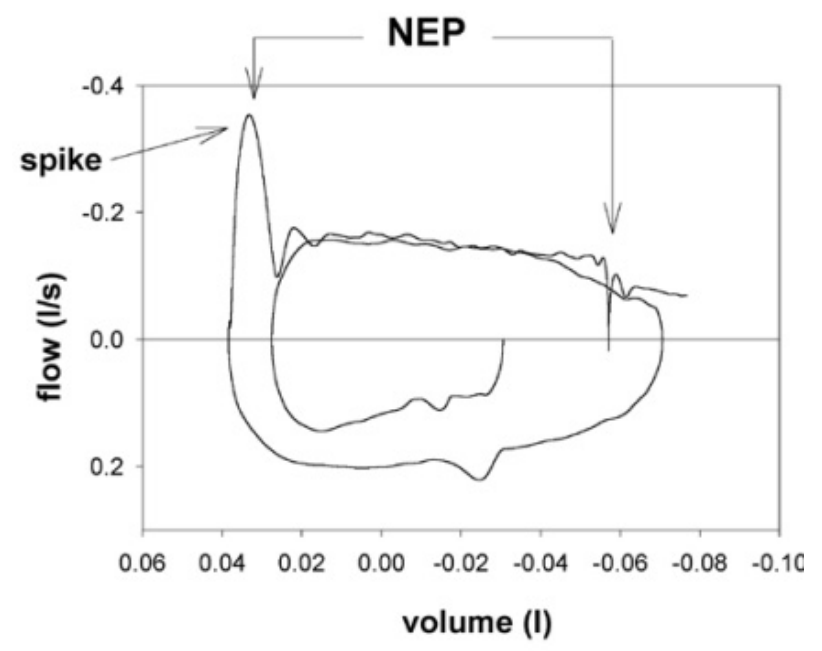

\section{c) collapses}

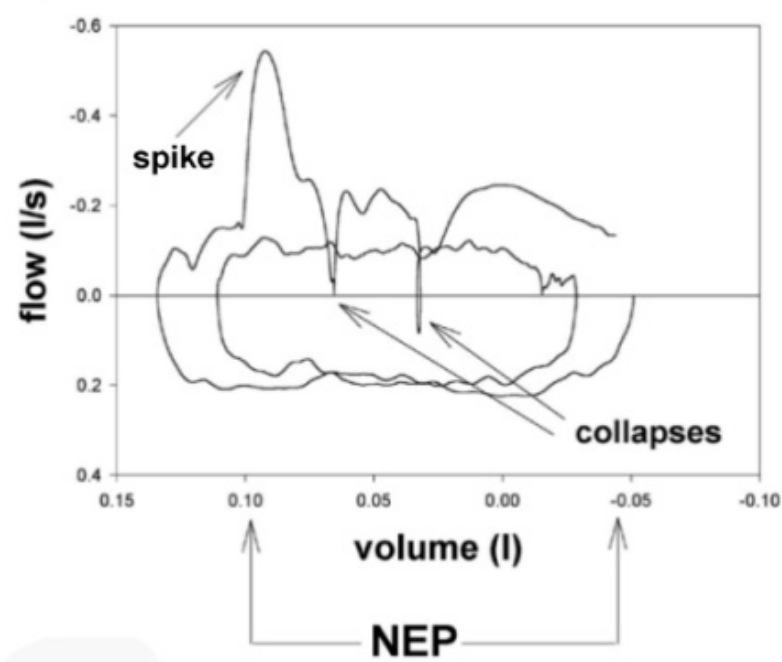

Fig. 1 a) Patient No. 24 (R group)

Flow - volume loops of negative expiratory pressure (NEP) test breath and preceding control breath of a patient without expiratory flow limitation, as indicated by increased flow with NEP trough expiration. For further information see text.

\section{b) Patient No. 9 ( $R$ group)}

Flow-volume loops of NEP test breath and preceding control breath of a patient with an intra thoracic expiratory flow limitation (FL), as indicated by the fact that the expiratory flow was the same with and without NEP. In this instance FL is >90\% of the tidal volume $\left(\mathrm{V}_{\mathrm{T}}\right)$.

\section{C) Patient No. 9 (NR group)}

Flow- volume loops of NEP test breath and preceding control breath in a subject exhibiting two transient reductions in flow below control with NEP, which reflect upper airway collapse (UAC). Otherwise the expiratory flow was higher with NEP than without and hence the patient did not exhibit intra thoracic FL. 


\section{Statistical analysis}

When comparing the studied groups we used the non-parametric $\chi^{2}$ test and Fischer test, which were adjusted for small numbers. The within-subject reproducibility of parameters was calculated as a coefficient of variation. Differences were evaluated by paired Student t-test. Values are given as means \pm SD and value of $p<0.05$ was taken as statistically significant.

\section{Results}

The frequency of tidal FL was significantly higher $(\mathrm{p}<0.001)$ in children of $\mathrm{R}$ group in comparison to NR subjects. The frequency of expiratory (extra-thoracic) AC did not differ significantly (Table 3 ). Tidal volume $\left(\mathrm{V}_{\mathrm{T}}\right)$ and a maximum inspiratory flow (insp $\mathrm{V}_{\text {max }}^{\prime}$ ) were similar in both groups; mid-expiratory flow $\left(\mathrm{V}_{\mathrm{E}}{ }^{\prime 50}\right)$ and flow at $25 \%$ of $\mathrm{V}_{\mathrm{T}}\left(\mathrm{V}_{\mathrm{E}}^{\prime} 25\right)$ also did not differ between groups (Table 3 ).

Table 3. Frequency and degree of flow limitation (FL) and upper airways collapse (UAC). Functional data during resting tidal breathing.

\begin{tabular}{lll}
\hline & $\mathbf{R}(\mathbf{n}=\mathbf{2 5})$ & $\mathbf{N R}(\mathbf{n}=\mathbf{1 7})$ \\
\hline$F L>75 \% V_{T}$ & $3(12 \%)$ & 0 \\
$F L 50-75 \% V_{T}$ & $1(4 \%)$ & 0 \\
$F L ~ 25-50 \% V_{T}$ & $5(20 \%)$ & 0 \\
$F L ~ 0-25 \% V_{T}$ & $3(12 \%)$ & 0 \\
$F L$ total & $12(48 \%)$ & 0 \\
UAC & $12(48 \%)$ & $5(29 \%)$ \\
$V_{T}(m l)$ & $189 \pm 105$ & $146 \pm 68$ \\
insp $V_{\text {max }}^{\prime}\left(l . s^{-1}\right)$ & $0.26 \pm 0.10$ & $0.19 \pm 0.10$ \\
$\exp V^{\prime} 25\left(l . s^{-1}\right)$ & $0.17 \pm 0.09$ & $0.13 \pm 0.07$ \\
$\exp V^{\prime} 50\left(l . s^{-1}\right)$ & $0.21 \pm 0.08$ & $0.17 \pm 0.09$ \\
\hline
\end{tabular}

Values are numbers (also in \%) of particular groups unless otherwise indicated. ${ }^{a} \mathrm{P}<0.001 \mathrm{R}$ vs. NR. Values are mean $\pm \mathrm{SD}$ unless otherwise indicated.

\section{Discussion}

Our experience shows that the NEP technique could be successfully applied in non-sedated newborns and infants as well as in preschool children. We found a high frequency of tidal FL in the $\mathrm{R}$ group while it was absent in the NR group. In contrast to adults, children appear to have a relatively high frequency of expiratory (extrathoracic) upper airway collapses, UAC (48 \% in RD group and $29 \%$ in the control group) (Table 3).

There are some problems regarding NEP application in small children, newborns and toddlers, which should be pointed out. The NEP technique has been recently accepted as a simple tool to assess tidal FL (Calverley and Kolouris 2005). This method is particularly useful in children, infants and newborns because it does not require patient's cooperation as it has been documented in the present study. About one third of preschool children (aged 3-5 years) cannot adequately perform the forced vital capacity maneuver (Zapletal and Chalupová 2003). Therefore, the NEP technique represents a tool for detection of airway obstruction without using a forced expiratory maneuver and without a need of a body plethysmograph (Johnson et al.1999, Calverley and Kolouris 2005).

The body posture could significantly influence the extent of tidal FL. The supine position enhances flow limitation (Valta et al. 1994, Boczkowski et al. 1997, Sulc et al. 1999, Eltayara et al. 2001). Therefore, the semi-recumbent $\left(45^{\circ}\right)$ position used in the present study might influence the prevalence and extent of FL. However, it is rather difficult to study this effect on FL in small children in upright and supine positions. Therefore no such studies were performed.

The neck position during the NEP testing should also be standardized. The maximal expiratory flow is increased in adults during a neck hyperextension (Mellisinos and Mead 1997). In our children the semirecumbent position with hyper-extended neck eliminated the negative effect on flow reduction. All our patients were tested in a semi-recumbent posture without a need of sedation, which implies the NEP technique can be applied to preschool children with a wide spectrum of diseases.

In the previous studies a wide range of applied NEP levels was used in children. Braggion et al. (1998) used a negative pressure about -4 and $-2 \mathrm{~cm} \mathrm{H}_{2} \mathrm{O}$, which did not elicit as clear-cut changes in $\mathrm{V}^{\text {‘ }}$ as the higher level, Tauber et al (2003) performed NEP $-3,-5$ and $-7 \mathrm{~cm} \mathrm{H}_{2} \mathrm{O}$ measurements in 43 children and they did not found any difference in FL depending on the NEP level. Jones et al. (2000) concluded that $-5 \mathrm{~cm} \mathrm{H}_{2} \mathrm{O}$ NEP in the supine position is applicable for infants up to 20 months of age during simultaneously applied pressure (by the jacket technique) of 30-100 hPa; it is important that an increase in flow (with both pressures applied) was less than $5 \%$.

The finding of one or more transient reductions of flow below control level reflects extrathoracic UAC 
(Fig. 1c). Since the frequency of UAC was higher in $\mathrm{R}$ group $(p=0.218)$, it might reflect the higher collapsibility of larger airways.

None of our subjects exhibited a decrease in flow with NEP below control flow throughout the expiration (Table 3). Consistently, it has also been found in all NEP tests in patients with obstructive sleep apnea syndrome (OSAS) (Verin et al. 2002, Baydur and MilicEmili 2004). Similarly, as shown recently, frequency of expiratory FL in aged population increased with respiratory and cardiac diseases (as compared with healthy elderly subjects) (de Bisschop et al. 2005). It might partly confirm our findings.

Application of negative expiratory pressure during expiration was demonstrated to influence oropharyngeal patency. In detail, NEP (ranging from -3 to $-10 \mathrm{~cm} \mathrm{H}_{2} \mathrm{O}$ ) applied at the onset of the expiration has only little influence on oropharyngeal muscle activity. In contrast, application of NEP at the end of expiration elicits above mentioned muscle activity. In other words, when NEP is applied in early expiration partial or total narrowing of upper airways cannot be ascribed to an impaired reflex activity of pharyngeal dilator muscles (Tantucci et al. 1998b)

Upper airway expiratory FL was also extensively studied in adult obese patients with obstructive sleep apnea (OSA) syndrome, but without any evidence of chronic obstructive lung disease (Insalaco et al 2005). Authors concluded that EFL (by the $\% \mathrm{~V}_{\mathrm{T}}$ evaluation) cannot distinguish between intrathoracic and extrathoracic origins of subjects' flow limitation. As the substantial contribution of this study is the finding that the NEP test is more usefully evaluated by a parameter of $\Delta \mathrm{V}^{\prime}$ (\%V' peak) than the "gold standard" of $\mathrm{FL}$ evaluation (i.e. $\% \mathrm{~V}_{\mathrm{T}}-$ see Methods section above).

Tantucci have studied healthy adult non-obese subjects without an evidence of OSA syndrome or upper airway abnormality (Tantucci et al. 1998a, Tantucci et al. 1998b). In the present study we did not detect any evidence of clinically significant upper airway abnormality (such as significant tonsillar hypertrophy and/or adenoid vegetation as well). We suggest that the maintenance of upper airway patency does not seem to be substantially influenced by an impaired reflex-mediated activation of major pharyngeal dilator muscle (m. genioglossus) both during expiratory and inspiratory phase.

Electrical stimulation of laryngeal and/or tracheobronchial region resulted in a reflex tracheo/ bronchoconstriction as the stimulation of nasal/ pharyngeal airway elicited sniff-like aspiration reflex with biphasic inspiratory pattern (an excitation followed by an inhibition - Tomori and Widdicombe 1969, Beňačka and Tomori 1995). Despite the fact that those studies have been performed in experimental condition we suggest an importance of the upper airway negative pressure reflex was also recently shown by Eckert et al. (2007). This issue is quite important in our pediatric subjects when an oro-nasal mask is currently used. Except of a brief communication by Scichilone et al. (2006) describing bronchoprotective effect of deep inspiration taken through the nose (versus that taken through the mouth) there is currently only scarce information available describing suspected deleterious effect of NEP applied through an oro-nasal mask in children; so, there is a must to study effects of high-level NEP applied in infancy and childhood.

Bronchodilators in adult asthma and COPD patients might affect the level of the end-expiratory lung volume and thus also the frequency or extent of FL itself (Boczkowski et al. 1997, Tantucci et al. 1998a, Tantucci et al. 1999, Hadcroft and Caverley 2001, Boni et al. 2002). The administration of salbutamol in 16 seated CF patients resulted in a significantly increased $\mathrm{FEV}_{1}(\mathrm{p}<0.02)$, but it had no effect on the extent of tidal FL in those patients (just in 3 of 16, i.e. $19 \%$ ) who exhibited tidal FL prior to salbutamol. No observations in children on effect of bronchodilators on FL have been published yet.

In conclusion, tidal FL can be easily assessed using the NEP method in non-cooperating infants and preschool children without any sedation. Children with respiratory diseases exhibited tidal FL more frequently and with a higher extent of $\% \mathrm{~V}_{\mathrm{T}}$ than children from control group. Further studies focused on effects of NEP in preschool children with upper airway occlusions (i.e., extra thoracic disorders such as adenoid vegetations and/or tonsilar hypertrophy) are required.

\section{Conflict of Interest}

There is no conflict of interest.

\section{Acknowledgements}

The authors wish to thank Marie Špírová and Soňa Horníčková for their technical assistance. The study was supported by the Grant NR 9131-3 of the Int. Grant Agency of the Czech Ministry of Health, the Research Initiative MSM - 111100008, by the Grant AV CR 1ET201210527 and by the Research Project No. MZO 00064203 / 6404 of the Czech Ministry of Health. 


\section{References}

BAYDUR A, MILIC-EMILI J: Expiratory flow limitation during spontaneous breathing. Comparison of patients with restrictive and obstructive respiratory disorders. Chest 112: 1017-1023, 1997.

BAYDUR A, WILKINSON L, MEHDIAN R, BAINS B, MILIC-EMILI J: Extra thoracic expiratory flow limitation in obesity and obstructive and restrictive disorders: effects of increasing negative expiratory pressure. Chest 125 : 98-105, 2004.

BEŇAČKA R, TOMORI Z: The sniff-like aspiration reflex evoked by electrical stimulation of the nasopharynx. Respir Physiol: 102: 163-174, 1995.

DE BISSCHOP C, MARTY ML, TESSIER JF, BERBERGER-GATEAU P, DARTIGUES JF, GUÉNARD H: Expiratory flow limitation and obstruction in the elderly. Eur Respir J 26: 594-601, 2005.

BOCZKOWSKI J, MURCIANO D, PICHOT MH, FERRETTI A, PARIENTE R, MILIC-EMILI J: Expiratory flow limitation in stable asthmatic patients during resting breathing. Am J Respir Crit Care Med 156: 752-757, 1997.

BONI E, CORDA L, FRANCHINI D, CHIROLI P, DAMIANI GP, PINI L, GRASSI V, TANTUCCI C: Volume effect and exertional dyspnoea after bronchodilator in patients with COPD with and without expiratory flow limitation at rest. Thorax 57: 528-32, 2002.

BRAGGION C, POLOSE G, FENZI V, CARLI MV, PRADAL U, MILIC-EMILI J: Detection of tidal expiratory flow limitation in infants with cystic fibrosis. Pediatr Pulmonol 25: 213-215, 1998.

CALVERLEY PMA, KOLOURIS NG: Flow limitation and dynamic hyperinflation: key concepts in modern respiratory physiology. Eur Respir J 25: 186-199, 2005.

DIAZ O, VILLAFRANCA C, GHEZZO H, BORZONE G, LEIVA A, MILIC-EMILI J, LISBOA C: Role of inspiratory capacity on exercise tolerance in COPD patients with and without tidal expiratory flow limitation at rest. Eur Respir J 16: 269-275, 2000.

DUGUET A, TANTUCCI C, LOZINGUEZ O et al: Expiratory flow limitation as determinant of orthopnea in patients with acute left heart failure. J Am Coll Cardiol 35: 690-700, 2000.

ECKERT DJ, MC EVOY, GEORGE KE, THOMSON KJ, CATCHESIDE PG: Genioglossus reflex inhibition to upperairway negative-pressure stimuli during wakefulness and sleep in healthy males. J Physiol Lond 581: 1193$1205,2007$.

ELTAYARA L, BECKLAKE MR, VOLTA CA, MILIC-EMILI J: Relationship between chronic dyspnea and e expiratory flow limitation in patients with chronic obstructive pulmonary disease. Am J Respir Crit Care Med 154: 1726-1734, 1996.

ELTAYARA L, GHEZZO H, MILIC-EMILI J: Orthopnea and tidal expiratory flow limitation in patients with stable COPD. Chest 119: 99-104, 2001.

FARRÉ R, NAVAJAS D, PESLIN R, ROTGER M, DUVIVIER C: A correction procedure for the asymmetry of differential pressure transducers in respiratory impedance measurements. IEEE Trans Biomed Eng 36: 1137-1140, 1989.

FERRETTI A, GIAMPICCOLO P, CAVALLI A, MILIC-EMILI J, TANTUCCI C: Expiratory flow limitation and orthopnea in massively obese subjects. Chest 119: 1401-1408, 2001.

GOETGHEBEUR D, SARNI D, GROSSI Y, LEROYER C, GHEZZO H, MILIC-EMILI J, BELLET M: Tidal expiratory flow limitation and chronic dyspnoea in patients with cystic fibrosis. Eur Repir J 19: 492-498, 2002.

GOLLOGLY S, SMITH JT, WHITE SK, FIRTH S, WHITE K: The volume of lung parenchyma as a function of age: a review of 1050 normal $\mathrm{C}$ scans of the chest with three-dimensional volumetric reconstruction of the pulmonary system. Spine 29: 2061-2066, 2004.

HADCROFT J, CAVERLEY PM: Alternative methods for assessing bronchodilator reversibility in chronic obstructive pulmonary disease. Thorax 56: 713-20, 2001.

HYATT RE: The interrelationships of pressure, flow, and volume during various respiratory maneuvers in normal and emphysematous subjects. Am Rev Respir Dis 83: 676-683, 1961. 
INSALACO G, ROMANO S, MARRONE O, SALVAGGIO A, BONSIGNORE G: A new method of negative expiratory pressure test analysis detecting upper airway flow limitation to reveal obstructive sleep apnea. Chest 128: $2159-2165,2005$.

JOHNSON BD, BECK KC, ZEBALLOS RJ, WEISMAN IM. Advances in pulmonary laboratory testing. Chest 116: $1377-$ $1387,1999$.

JONES MH, DAVIS SD, KISLING JA, HOWARD JM, CASTILE R, TEPPER RS: Flow limitation in infants assessed by negative expiratory pressure. Am J Respir Crit Care Care Med 161: 713-717, 2000.

KOLOURIS NG, VALTA P, LAVOIE A, CORBEIL C, CHASSE M, BRAIDY J, MILIC-EMILI J: A simple method to detect expiratory flow limitation during spontaneous breathing. Eur Respir J 8: 306-313, 1995.

KOLOURIS NG, RETSOU S, KOSMAS E, DIMAKOU K, MALAGARI K, MANTZIKOPOULOS G, KOUTSOUKOU A, MILIC-EMILI J, JORDANOGLOU J: Tidal expiratory flow limitation, dyspnea and exercise capacity in patients with bilateral bronchiectasis. Eur Respir J 21: 743-748, 2003.

MELLISINOS CG, MEAD J: Maximum expiratory flow changes induced by longitudinal tension on the trachea in normal subjects. J Appl Physiol 43: 537-544, 1977.

MILIC-EMILI J: Expiratory flow limitation: Roger S. Mitchell Lecture. Chest 117 (5 Suppl 1): 219S-223S, 2000.

PANKOW W, PODSZUS T, GUTHEIL T, PENZEL T, PETER J, VON WICHERT P: Expiratory flow limitation and intrinsic positive end-expiratory pressure in obesity $J$ Appl Physiol 85: 1236-1243, 1998.

PESLIN R, JARDIN P, DUVIVIER C, BEGIN P. In-phase rejection requirements for measuring respiratory input impedance. J Appl Physiol 56: 804-809, 1984.

SCICHILONE N, PYRGOS G, BELLIA V, TOGIAS A: Inspiration through the nose increases the bronchoprotective effect of lung inflation. J Allergy Clin Immunol 119: 501-503, 2007.

STOCKS J: Clinical implications of pulmonary function testing in preschool children. Paediatr Respir Rev 7 (Suppl 1): 26-29, 2006.

SUlC J, VOLTA CA, PLOYSONGSANG Y, ELTAYARA L, OLIVENSTEIN R, MILIC-EMILI J: Flow limitation and dyspnea in normal supine subjects during metacholine challenge. Eur Respir J 14: 1326-1331, 1999.

TANTUCCI C, DUGUET A, SIMILOWSKI T, ZELTER M, DERENNE JP, MILIC-EMILI J: Effect of salbutamol on dynamic hyperinflation in chronic obstructive pulmonary disease patients. Eur Respir J 12: 799-804, $1998 \mathrm{a}$.

TANTUCCI C, MEHIRI S, DUGUET A, SIMILOWSKI T, AMULF I, ZELTER M, DERENNE JP, MILIC-EMILI J: Application of negative expiratory pressure during expiration and activity of genioglossus in humans. $J$ Appl Physiol 84: 1076-1082, 1998 b.

TANTUCCI C, ELLAFFI M, DUGUET A, ZELTER M, SIMILOWSKI T, DERENNE JP, MILIC-EMILI J: Dynamic hyperinflation and flow limitation during methacholine-induced bronchoconstriction in asthma. Eur Respir $J$ 14: 295-301, 1999.

TAUBER E, FAZEKAS T, EICHLER I, EICHSTILL CH, PARTNER CH, KOLLER D Y, FISCHER T: Negative expiratory pressure: A new tool for evaluating lung function in children? Pediatr Pulmonol 35: 162-168, 2003.

TOMORI Z, WIDDICOMBE JG: Muscular, bronchomotor and cardiovascular reflexes elicited by mechanical stimulation of the respiratory tract. J Physiol Lond 200: 25-49, 1969.

TORCHIO R, GULOTTA C, PERBONI A, CIACCO C, GUGLIELMO M, ORLANDI F, MILIC-EMILI J: Orthopnea and tidal expiratory flow limitation in patients with euthyroid goiter. Chest 124: 133-140, 2003.

VALTA P, CORBEIL C, LAVOIE A, CAMPODONICO R, KOLOURIS N, CHASSE M, BRAIDY J, MILIC-EMILI $\mathrm{J}$ : Detection of expiratory flow limitation during mechanical ventilation. Am J Respir Crit Care Med 150: 1311-1317, 1994.

VERIN E, TARDIF C, PORTIER F, SIMILOWSKI T, PASQUIS P, MUIR JF: Evidence for expiratory flow limitation of extrathoracic origin in patients with obstructive sleep apnoea. Thorax 57: 423-428, 2002.

ZAPLETAL A, CHALUPOVÁ J: Forced expiratory parameters in healthy preschool children (3-6 years of age). Pediatr Pulmonol 35: 200-207, 2003. 